\title{
Regulatory T lymphocytes/Th17 lymphocytes imbalance in autism spectrum disorders: evidence from a meta-analysis
}

\author{
Pierre Ellul $1^{1,2^{*}}$ (D), Michelle Rosenzwajg ${ }^{2,3}$, Hugo Peyre $^{1,4}$, Gwladys Fourcade ${ }^{2}$, Encarnita Mariotti-Ferrandiz ${ }^{2}$,
} Vincent Trebossen ${ }^{1}$, David Klatzmann ${ }^{2,3+}$ and Richard Delorme ${ }^{1,5+}$

\begin{abstract}
Background: Immune system dysfunction has been proposed to play a critical role in the pathophysiology of autism spectrum disorders (ASD). Conflicting reports of lymphocyte subpopulation abnormalities have been described in numerous studies of patients with ASD. To better define lymphocytes abnormalities in ASD, we performed a metaanalysis of the lymphocyte profiles from subjects with ASD.

Methods: We used the PRISMA recommendations to query PubMed, Embase, PsycholNFO, BIOSIS, Science Direct, Cochrane CENTRAL, and Clinicaltrials.gov for terms related to clinical diagnosis of ASD and to lymphocytes' populations. We selected studies exploring lymphocyte subpopulations in children with ASD. The search protocol has been registered in the international Prospective Register of Systematic Reviews (CRD42019121473).

Results: We selected 13 studies gathering 388 ASD patients and 326 healthy controls. A significant decrease in the CD4+ lymphocyte was found in ASD patients compared to controls $[-1.51(95 \% \mathrm{Cl}-2.99 ;-0.04) p=0.04]\left(P^{2}=96 \%\right.$ [95\% Cl 94.6, 97.7], $p<0.01$ ). No significant difference was found for the CD8+T, B and natural killer lymphocytes. Considering the CD4+ subpopulation, there was a significant decrease in regulatory T lymphocytes (Tregs) in ASD patients $(n=114)$ compared to controls $(n=107)[-3.09(95 \% \mathrm{Cl}-4.41 ;-1.76) p=0.0001] ;\left(I^{2}=90.9 \%,[95 \% \mathrm{Cl} 76.2\right.$, 96.5], $p<0.0001)$ associated with an increase oin the Th17 lymphocytes (ASD; $n=147$ controls; $n=128)[2.23(95 \% \mathrm{Cl}$ $0.79 ; 3.66) p=0,002]\left(I^{2}=95.1 \%[95 \% \mathrm{Cl} 90.4,97.5], p<0.0001\right)$.

Limitations: Several factors inducing heterogeneity should be considered. First, differences in the staining method may be responsible for a part in the heterogeneity of results. Second, ASD population is also by itself heterogeneous, underlying the need of studying sub-groups that are more homogeneous.

Conclusion: Our meta-analysis indicates defects in CD4+ lymphocytes, specifically decrease oin Tregs and increase in Th17 in ASD patients and supports the development of targeted immunotherapies in the field of ASD.
\end{abstract}

Keywords: ASD, Immunology, Peripheral blood, Regulatory T lymphocyte, Th17 lymphocytes

*Correspondence: pierre.ellul@aphp.fr

†David Klatzmann and Richard Delorme co-senior authors.

1 AP-HP (Assistance Publique-Hôpitaux de Paris), Robert Debré Hospital,

Child and Adolescent Psychiatry Department, Paris University, 48 Boulevard Sérurier, 75019 Paris, France

Full list of author information is available at the end of the article

\section{Background}

Autism spectrum disorders (ASD) define a heterogeneous group of neurodevelopmental disorders characterized by a deficit in social communication associated with restrictive, repetitive and stereotyped behaviors [1]. ASD affects about 1 in 54 people in the general population with a burden of 58 Disability Adjusted Life Years original author(s) and the source, provide a link to the Creative Commons licence, and indicate if changes were made. The images or other third party material in this article are included in the article's Creative Commons licence, unless indicated otherwise in a credit line to the material. If material is not included in the article's Creative Commons licence and your intended use is not permitted by statutory regulation or exceeds the permitted use, you will need to obtain permission directly from the copyright holder. To view a copy of this licence, visit http://creativecommons.org/licenses/by/4.0/. The Creative Commons Public Domain Dedication waiver (http://creativeco mmons.org/publicdomain/zero/1.0/) applies to the data made available in this article, unless otherwise stated in a credit line to the data. 
per 100,000 individuals [2]. The neurobiology of ASD remains largely unknown although many genetic associations, as well as complex gene-environment interactions have been reported $[3,4]$. The immune system seems to play a crucial role in the etiology of ASD. Several studies linked ASD with personal/familial history of autoimmune disorders such as diabetes mellitus, celiac disease, autoimmune thyroiditis, rheumatoid arthritis, psoriasis, systemic lupus erythematosus $[5,6]$. Post-mortem analysis of brain tissues from individuals with ASD has shown two main disrupted biological pathways: a down-regulation of the genes associated with synaptic functions and an up-regulation of immune-related genes such as the genes involved in the M2-microgial cell states, or in the interferon and cell signaling pathways [7, 8]. Alterations of the peripheral immune system have also been reported with quantitative and qualitative immune dysfunctions, specifically abnormal lymphocyte subpopulations [5].

B-, T- and NK-cells, are closely linked in a dynamic balance [9]. Any modification of one of these subpopulations affects the whole pattern of immune cells and therefore, affects the homeostasis of the human body [10]. Lymphocytes, well known for their roles against pathogens, have also several functions devoted to organ-specific homeostasis [9]. For example, regulatory T cells (Tregs), a subset of $\mathrm{T}$ lymphocytes, are involved in the maintenance of the immune system homeostasis [10], tissue regeneration [11] and in maternal and fetal cardiomyocyte proliferation during pregnancy [12]. The immune system has also a critical role in neurodevelopment and associated functions [13]. For example, cytokines have a central physiological role in brain development, cognitive functions and behavioral regulation such as interleukin-1 beta in synapses formation and contextual learning, interleukin 4 in promoting neurogenesis and spatial learning or interleukin 17a (IL-17a) for synaptic plasticity and the regulation of anxiety (for a complete review see [14, 15]). It should also be cited the fundamental role of the complement in synaptic pruning during normal brain development [16]. Thus, an immune system disruption may affect the structural micro-architecture of the brain and the underlined cognitive functions [17].

In ASD, several studies reported changes in peripheral blood lymphocyte subsets such as reduced total number of lymphocytes, impairment of the CD4/ CD8 $\mathrm{T}$ cell ratio, a defective activation of $\mathrm{T}$ cells, an increased number of the natural killer (NK) cells, an imbalance of the Th1/Th2 cytokines but also some aberrations in cytotoxicity related to NK cells (for review see [18]). Additional reports showed also the presence of autoantibodies directed toward central nervous system (CNS) proteins, suggesting a deregulation of B lymphocytes [19]. In animal models of ASD, similar immune alterations were reported, showing an association between abnormal CNS development and ASD-like behaviors in pups [5]. For example, higher proportion of pro-inflammatory lymphocytes or altered NK cell activity induced abnormal cortical development, stereotyped behaviors, and social communication deficit in mice [20].

\section{Aims of the study}

These preliminary findings support a striking link between ASD and immune dysfunctions. However, studies on lymphocyte subpopulation in ASD have reported conflicting results. We thus, conducted a systematic review and meta-analysis to identify specific abnormal lymphocyte imbalance in ASD.

\section{Methods and materials}

\section{Search strategy}

The protocol for the present systematic review/metaanalysis was registered on the international Prospective Register of Systematic Reviews PROSPERO (protocol number: CRD42019121473). The systematic review and meta-analysis were conducted and reported following the Preferred Reporting Items for Systematic review and Meta-Analysis (PRISMA) recommendations [21]. The following electronic databases were searched with no restriction in terms of language, type of document, or date: PubMed (MEDLINE), Embase, PsychoINFO, BIOSIS, Science Direct, and Cochrane CENTRAL. The following search terms/syntax were used for Pubmed: (autism[tiab] OR Asperger[tiab] OR autism spectrum disorder[tiab] OR pervasive developmental disorder[tiab] OR autistic[tiab] OR ASD[tiab] OR PDD[tiab]) AND (lymphocytes[tiab] OR CD3[tiab] OR T cells[tiab] OR Natural Killer[tiab] OR CD56 lymphocyte[tiab] OR CD4 lymphocyte[tiab] OR CD8 lymphocyte[tiab] OR B lymphocyte[tiab] or B cells[tiab] OR CD20[tiab] OR Regulatory $\mathrm{T}$ lymphocyte[tiab] OR Foxp3[tiab] OR Th1 lymphocyte[tiab] OR Th2 lymphocyte[tiab] OR T9 lymphocyte[tiab] OR Th17 lymphocyte[tiab] OR GATA 3[tiab] OR T-bet[tiab] OR RORgt[tiab] OR $\gamma \delta \mathrm{T}$ cells[tiab] OR unconventional $\mathrm{T}$ cells[tiab] OR MAIT[tiab]).

The search terms/syntax were adapted accordingly for the other databases. Reference lists of the retained articles and relevant review articles were hand-searched to retrieve any additional pertinent reports not detected via the electronic database search. Furthermore, we used the Clinicaltrials.gov website to identify any relevant studies not yet published as full text articles at the time of the search. The last search was completed on January 2021. 


\section{Selection of the relevant articles}

We only included in our systematic review case-control studies which included participants with a mean age under 18 years old with a diagnosis of Autism, Asperger, pervasive developmental disorder (PDD) or ASD, in which the authors explored one or more lymphocyte subpopulations.

\section{Selection of studies and data extraction}

The eligibility process was conducted in two separate stages: (1) two researchers (PE and HP) independently screened all non-duplicated references initially retrieved as potentially pertinent and excluded those clearly not pertinent based on title or abstract. A final list was agreed with discrepancies resolved by consensus between the two authors. When consensus was not reached, a third, senior researcher (RD) acted as arbitrator; (2) the full-text version of the articles passing stage 1 screening were downloaded and assessed for eligibility by the two researchers, independently. Discrepancies were resolved by consensus between the two researchers and, if needed, the third senior researcher acted as arbitrator. When required, corresponding authors were contacted to clarify study eligibility and gather unpublished data.

\section{Statistical analyses}

The difference between each study was first calculated as the lymphocyte value in the ASD group minus the lymphocyte value in the control group, divided by the pooled pre-test standard deviation with a bias adjustment [22]. The difference for each study was then combined using the inverse variance method. Given the inherent heterogeneity of studies, random-effects models were used. Heterogeneity was statistically assessed by estimating $I^{2}$, $\tau^{2}$ and $p$-value of heterogeneity test. The statistic $I^{2}$ was calculated to estimate between-study heterogeneity. $\mathrm{I}^{2}$ represents the percentage of variance due to betweenstudies factors rather than sampling error [23]. $\tau^{2}$ statistic provides a measure of the variability of the effect estimate across studies in a random-effects model [24]. Analyses were performed in $\mathrm{R}$ by use of the metabin command from the package meta.

\section{Results}

\section{Characteristics of studies included in the meta-analysis}

Based on our selection criteria (Fig. 1 \& Additional file 1: table 1), we included 13 studies gathering 388 individuals with autism and 326 healthy controls [2537]. Seven studies analyzed the $C D 4+T$ lymphocytes (LT4) (194 cases and 152 controls), four the CD8+ T lymphocytes (LT8) (124 cases and 83 controls), three the Tregs subpopulation (114 cases and 107 controls),

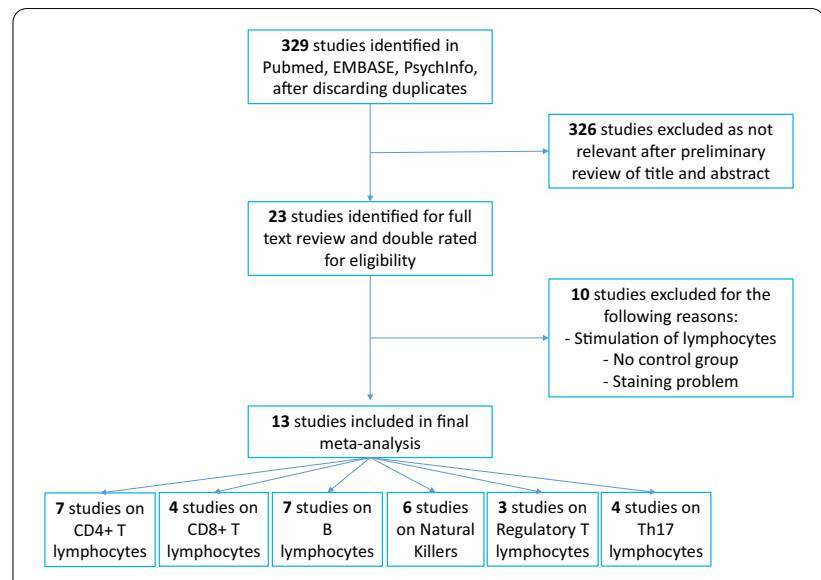

Fig. 1 Flowchart of studies included

seven the B lymphocytes (LB) (194 cases and 152 controls), six the NK cells (176 cases and 138 controls) and four the Th17 T-cells (Th17) (147 cases and 128 controls). No data were available for the others lymphocyte subpopulations including in our search strategy. Details of included studies can be found in Additional file 2: table 2, Additional file 3: table 3, Additional file 4: table 4, Additional file 5: table 5, Additional file 6: table 6, Additional file 7: table 7.

\section{Results of the meta-analysis}

We first explored the association between the CD4+ T lymphocytes, CD8+T lymphocytes, LB and NK cells with ASD (Fig. 2). We observed a significant decrease in the peripheral blood CD4+ $\mathrm{T}$ lymphocytes in ASD compared to healthy controls $[-1.51$ (95\% CI-2.99; - 0.04) $p=0.04]$ with a significant heterogeneity $\left(I^{2}=96 \%\right.$ [95\% CI 94.6, 97.7], $\left.p<0.01\right)$. We observed no significant differences between ASD and controls for the peripheral blood CD8+ T lymphocytes, LB and NK cells $[0.05$ (95\% CI -0.36 ; 0.47$)$ $p=0.8 ;-0.50(95 \% \mathrm{CI}-1.12 ; 0.11) p=0.11$; and 0.15 $(95 \% \mathrm{CI}-0.67 ; 0.97) p=0.7$, respectively].

Considering Tregs and Th17 subpopulations (Fig. 3), we observed a significant decrease in Tregs cells $[-3.09$ $(95 \% \mathrm{CI}-4.41 ;-1.76) p=0.0001]$ in ASD peripheral blood cells compared to controls $\left(I^{2}=90.9 \%\right.$, [95\% CI 76.2, 96.5], $p<0.0001)$. We also found a significant increase oin the Th17 cells in ASD [2.23 (95\% CI 0.79 ; 3.66) $p=0.002]\left[I^{2}=95.1 \%\right.$ [95\% CI 90.4, 97.5], $p<0.0001]$ compared to controls. Due to methodological limits, we were unable to calculate the Treg/Th17 ratio. Due to lack of data we were also unable to study the other lymphocyte subpopulations included in the search protocol. 

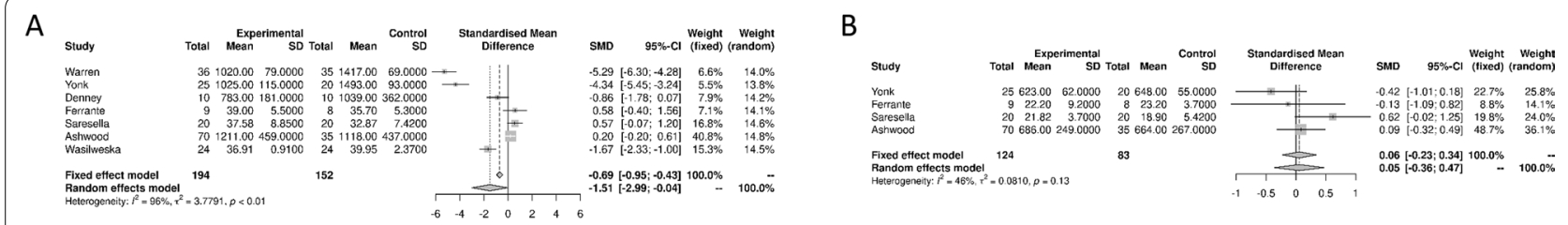

C

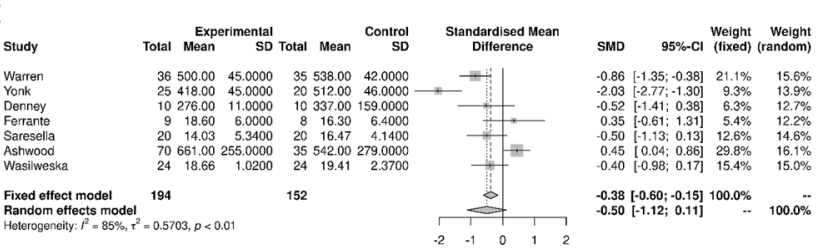

D

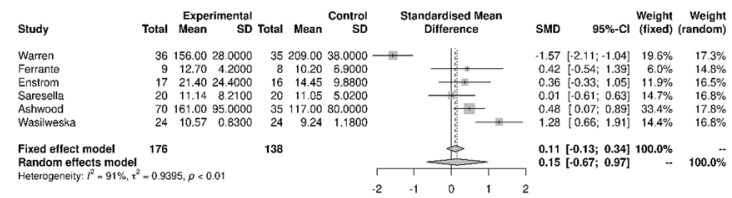

Fig. 2 Forest plots of the distinct lymphocyte subpopulations in autism spectrum disorders compared to controls. A T CD4+ lymphocytes; B T CD8+ lymphocytes; C B Lymphocytes; D natural killer cells

A

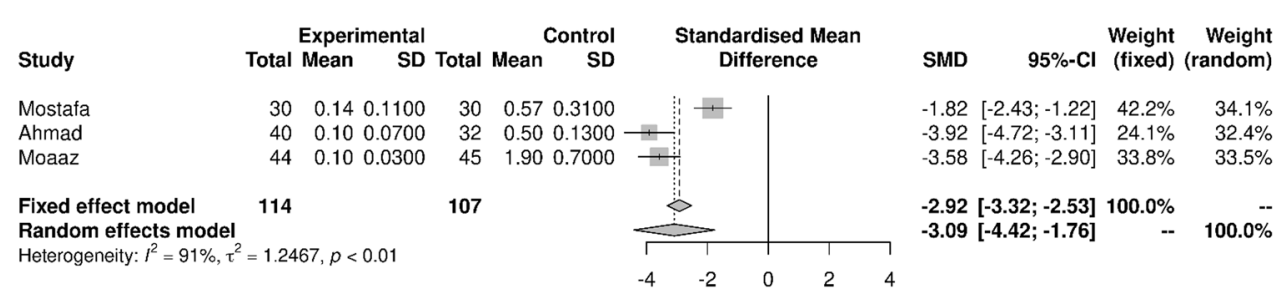

B

\begin{tabular}{|c|c|c|c|c|}
\hline \multirow[b]{2}{*}{ Study } & \multicolumn{2}{|r|}{ Experimental } & \multicolumn{2}{|r|}{ Contro } \\
\hline & Total & Mean & Total & Mean \\
\hline Onore & 18 & 1.901 .3900 & 16 & 1.300 .7600 \\
\hline Ahmad & 40 & 0.200 .0710 & 32 & 0.100 .0500 \\
\hline Moaz & 44 & $2.70 \quad 0.8000$ & 45 & 0.100 .0200 \\
\hline Nadeem & 45 & 2.030 .5721 & 35 & 0.870 .3705 \\
\hline $\begin{array}{l}\text { Fixed effect model } \\
\text { Random effects model } \\
\text { Heterogeneity: } I^{2}=95 \%, \tau^{2}\end{array}$ & 147 & $372, p<0.01$ & 128 & \\
\hline
\end{tabular}

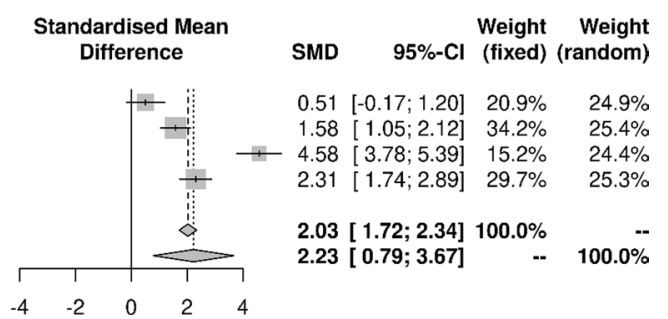

Fig. 3 Forest plots of the distinct lymphocyte subpopulations in autism spectrum disorders compared to controls. A Regulatory T lymphocytes; B Th17 Lymphocytes

\section{Discussion}

Our meta-analysis pointed toward abnormalities of the number of peripheral CD4+lymphocyte and especially Th17 and Tregs cells in patients with ASD.

Th17 are pro-inflammatory CD4+ T cells that are associated with inflammatory immune response in infection or autoimmune disorders [46], but may also regulate brain architecture and behaviors [38]. Tregs are a subset of $\mathrm{CD} 4+\mathrm{T}$ cells critical for the maintenance of the immune system homeostasis and peripheral tolerance. Brain Tregs cells also play an important role in myelination through regeneration/protection mechanisms [13]. Thus, the biological properties of Th17 cells and Tregs in the brain might be related to the observed pathophysiology of ASD.
The differentiation of naïve $\mathrm{T}$ cell precursors into Tregs or Th17 depends on the cytokine environment. Indeed, TGF-B and IL-2 induce Tregs whereas TGF-B and IL6, Th17 cells. Those cytokines act in part through the up-regulation (for Th17) or down-regulation (for Tregs) of the mammalian target of rapamycin (mTOR) complex $[39,40]$. In neurons or Purkinje cell, mTOR complex has a major role in brain development and neuron homeostasis [41] and is severely affected in ASD related syndromes such as the tuberous sclerosis. In peripheral blood mononuclear cells, overexpression of the mTOR pathway in patients with ASD [42] has recently been associated with increased expression of the Th17 specific transcription factor (Roryt) and reduced expression of the Treg transcription factor 
(Foxp3). Thus, the transcription factor anomalies found in ASD are also consistent with our results showing a decrease in Tregs and increase in Th17.

From a clinical point of view, our results are also relevant for the co-morbidities observed in ASD. First, there is a significant increase in the prevalence of atopic diseases (including allergy and asthma) among patients with ASD [43]. If Th2 lymphocytes orchestrate immune responses in atopic diseases [44], Tregs is of major importance in maintaining tolerance to several antigens, thus playing a central role in allergy [45]. For example, a relative or absolute defect in Tregs in airways bias immune response toward Th2 leading to allergic inflammatory diseases [46]. In line with these data, unstable Tregs phenotype has been found in asthmatic patients and is associated with a more severe disease. Collectively, these data pointed to a central role of Tregs in atopic diseases [46]. Thus, we postulate that the decrease in Tregs observed in ASD patients could be, at least in part, responsible for this observed comorbidity. Secondly, individuals with ASD have long been associated with an increase in gastrointestinal symptoms (diarrhea/constipation) and intestinal permeability, related to an alteration in the microbiota composition [47]. Indeed, recent meta-analysis found low Bifidobacterium and higher proportion of Bacteroides, Parabacteroides, Clostridium phyla in ASD patients [48]. Microbiota composition is closely intricated with lymphocytes subtype development and function (especially Tregs and Th17). For example, while segmented filamentous bacteria promote the development of Th17 cells, Bifidobaberitum induced Tregs [49]. Although no formal causal role can be established, we hypothesized that the decrease in Tregs and increase in Th17 found may be related to microbial dysbiosis.

Interestingly, a similar lymphocyte pattern has been found in several different mouse models of ASD, suggesting that imbalance of Treg and Th17 lymphocytes may be an important common physiopathological pathway in autism (see Additional file 8: table 8). Unfortunately, due to the low number of studies and the various gating strategies, we were unable to carry out analyses of these animal studies. Interestingly in a mouse model of ASD, IL-17 injected directly in the brain transiently reversed the ASD-like symptomatology, suggesting a possible physiological role of IL-17a lymphocytes in the CNS, later confirmed by a recent study [50]. These data may seem contradictory to our results but may also mean that the lymphocyte profile observed in the periphery is different from that in the brain. As seen in MIA model, IL-17a secreted by mother during pregnancy induce ASD. Thus, another possible explanation is that IL-17a may have different effects on brain development depending on the timing of exposure. Our findings highlight the need for further research to better understand the intriguing role of Treg, Th17 and IL-17 in ASD.

\section{Limitations}

Our results should be taken in light of the strengths and limits of the study. Several factors inducing heterogeneity should be considered. The different lymphocytes populations are separated by flow cytometry and the staining strategy is not precisely the same in all the studies, indicated that we may not be looking exactly at the same cells. This difference in the staining method might be responsible for a part in the heterogeneity of results. It is also important to note that in the general population, the frequency of the different subgroups within $\mathrm{T}$ cells can vary from a normal range of 22 to $93 \%$ of the total lymphocytes [51]. Despite this, we still have found differences and comparing such variable populations reinforces the power of our results [52, 53]. Lastly, ASD population is also by itself heterogeneous, underlying the need of studying sub-groups that are more homogeneous. Because we found significant differences despite factors inducing heterogeneity, our main results could be considered as robust and relevant. Results on lymphocyte subpopulation-Tregs, Th17-should also be taken with precaution. Indeed, because those populations are more precise, we used more stringent staining protocols. As a consequence, we limit the number of studies per analysis, losing power but increasing sensibility. Because no study screened them, it is also important to note that several lymphocytes subpopulation (see research algorithm) were not included in this meta-analysis and may have a role to play in the pathophysiology of ASD. Furthermore, due to lack of data, we were not able to analyze data from other tissues than peripheral blood. Therefore, it is important to note that our work focuses on peripheral populations and does not prejudge immune changes within the CNS. For the strengths of our study, by using the criteria of the PRISMA statement, we performed a systematic search in several databases, without language restrictions, as well as in Clinicaltrials.gov. We have also contacted authors to gathered additional unpublished data, limiting the publication bias. Thus, we have included an important number of studies, with more than 700 subjects.

\section{Conclusion}

More than immunological abnormalities in ASD, we claim for more homogeneous and precise immunological studies in the field of psychiatry. In line with this idea, further large-scale studies on ASD patients should be done. Next, experimental animal studies should be performed to delineate the type of immune intervention aimed in ASD. We can hope that these findings 
will pave new avenues for therapeutic strategies involving the immune-modulation in ASD.

\author{
Abbreviations \\ ASD: Autism spectrum disorders; CNS: Central nervous system; LB: B lympho- \\ cytes; LT4: CD4+T lymphocytes; LT8: CD8+T lymphocytes; mTOR: Mammalian \\ target of rapamycin; PDD: Pervasive developmental disorder; Th17: Th17T-cells; \\ Treg: Regulatory T lymphocytes.
}

\section{Supplementary Information}

The online version contains supplementary material available at https://doi. org/10.1186/s13229-021-00472-4.

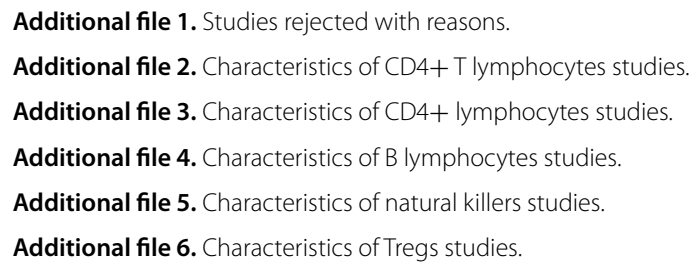

Additional file 8. Characteristics of mice studies with lymphocytes subpopulations.

\section{Acknowledgements}

We would like to thank all the authors who have kindly provided additional unpublished information/data: M. Saresella and colleagues, Don C. Gnocchi Foundation, Milano, Italy. GA. Mostafa and colleagues, Department of Pediatrics, Faculty of Medicine, Ain Shams University, Nasr City, Cairo, Egypt. SF. Ahmad and colleagues, Department of Pharmacology and Toxicology, College of Pharmacy, King Saud University, Riyadh, Kingdom of Saudi Arabia. P. Ashwood and colleagues, Department of Medical Microbiology and Immunology, and The Medical Investigation of Neurodevelopmental Disorders Institute, University of California, Davis, CA, USA. NM. Ponzio and colleagues, Department of Pathology, Rutgers New Jersey Medical School and Rutgers School of Graduate Studies, Newark, USA. SK. Mazmanian, Division of Biology and Biological Engineering, California Institute of Technology, East California Boulevard, Pasadena, USA. R. Luan and colleagues, State Key Laboratory of Medicinal Chemical Biology, College of Life Sciences, Nankai University, Tianjin, China. S. Kim, Division of Infectious Diseases and Immunology and Program in Innate Immunity, Department of Medicine, University of Massachusetts Medical School, Worcester, Massachusetts 01605, USA.

\section{Authors' contributions}

PE did the bibliography, extracted the data, did the statistical analysis, and wrote the first draft of the report. HP helped on the statistical analysis. EMF, MR, GF, and VT gave input for the draft. DK and RD supervised the work and gave input. All authors read and approved the final manuscript.

\section{Funding}

None.

\section{Availability of data and materials}

All data generated or analyzed during this study are included in this published article and its supplementary information files.

\section{Declarations}

Ethics approval and consent to participate

Not applicable.

\section{Consent for publication}

Not applicable.

\section{Competing interests}

The authors declare that they have no competing interests.

\section{Author details}

${ }^{1}$ AP-HP (Assistance Publique-Hôpitaux de Paris), Robert Debré Hospital, Child and Adolescent Psychiatry Department, Paris University, 48 Boulevard Sérurier, 75019 Paris, France. ${ }^{2}$ INSERM, Immunology-Immunopathology-Immunotherapy (i3), Sorbonne Université, Paris, France. ${ }^{3}$ AP-HP, Hôpital Pitié-Salpêtrière, Biotherapy (CIC-BTi), Paris, France. ${ }^{4}$ Robert Debré Hospital, UMR 1141, NeuroDiderot Inserm - Paris University, Paris, France. ${ }^{5}$ Human Genetics and Cognitive Functions, Institut Pasteur, Paris, France.

Received: 12 March 2021 Accepted: 29 September 2021

Published online: 12 October 2021

\section{References}

1. Diagnostic and Statistical Manual of Mental Disorders: DSM-5. 5th ed. Washington: American psychiatric association; 2013.

2. Baxter AJ, Brugha TS, Erskine HE, Scheurer RW, Vos T, Scott JG. The epidemiology and global burden of autism spectrum disorders. Psychol Med. 2015;45:601-13.

3. Barak B, Feng G. Neurobiology of social behavior abnormalities in autism and Williams syndrome. Nat Neurosci. 2016;19:647-55.

4. Delorme R, Ey E, Toro R, Leboyer M, Gillberg C, Bourgeron T. Progress toward treatments for synaptic defects in autism. Nat Med. 2013;19:685-94.

5. Estes ML, McAllister AK. Immune mediators in the brain and peripheral tissues in autism spectrum disorder. Nat Rev Neurosci. 2015;16:469-86.

6. Gesundheit B, Rosenzweig JP, Naor D, Lerer B, Zachor DA, Procházka V, et al. Immunological and autoimmune considerations of autism spectrum disorders. J Autoimmun. 2013;44:1-7.

7. Voineagu I, Wang X, Johnston P, Lowe JK, Tian Y, Horvath S, et al. Transcriptomic analysis of autistic brain reveals convergent molecular pathology. Nature. 2011;474:380-4.

8. Gupta S, Ellis SE, Ashar FN, Moes A, Bader JS, Zhan J, et al. Transcriptome analysis reveals dysregulation of innate immune response genes and neuronal activity-dependent genes in autism. Nat Commun. 2014;5:5748.

9. DuPage M, Bluestone JA. Harnessing the plasticity of CD4(+) T cells to treat immune-mediated disease. Nat Rev Immunol. 2016;16:149-63.

10. Lu L, Barbi J, Pan F. The regulation of immune tolerance by FOXP3. Nat Rev Immunol. 2017;17:703-17.

11. Li J, Tan J, Martino MM, Lui KO. Regulatory T-cells: potential regulator of tissue repair and regeneration. Front Immunol. 2018;9:585.

12. Zacchigna S, Martinelli V, Moimas S, Colliva A, Anzini M, Nordio A, et al. Paracrine effect of regulatory $T$ cells promotes cardiomyocyte proliferation during pregnancy and after myocardial infarction. Nat Commun. 2018;9:2432.

13. Dombrowski Y, O'Hagan T, Dittmer M, Penalva R, Mayoral SR, Bankhead P, et al. Regulatory $T$ cells promote myelin regeneration in the central nervous system. Nat Neurosci. 2017. https://doi.org/10.1038/nn.4528.

14. Salvador AF, de Lima KA, Kipnis J. Neuromodulation by the immune system: a focus on cytokines. Nat Rev Immunol. 2021;21:526-41.

15. Zengeler KE, Lukens JR. Innate immunity at the crossroads of healthy brain maturation and neurodevelopmental disorders. Nat Rev Immunol. 2021;21:454-68.

16. Stephan AH, Barres BA, Stevens B. The complement system: an unexpected role in synaptic pruning during development and disease. Annu Rev Neurosci. 2012;35:369-89.

17. Klein RS, Garber C, Howard N. Infectious immunity in the central nervous system and brain function. Nat Immunol. 2017;18:132-41.

18. Gładysz D, Krzywdzińska A, Hozyasz KK. Immune abnormalities in autism spectrum disorder-could they hold promise for causative treatment? Mol Neurobiol. 2018;55:6387-435.

19. Brimberg L, Sadiq A, Gregersen PK, Diamond B. Brain-reactive IgG correlates with autoimmunity in mothers of a child with an autism spectrum disorder. Mol Psychiatry. 2013;18:1171-7.

20. Choi GB, Yim YS, Wong H, Kim S, Kim H, Kim SV, et al. The maternal interleukin-17a pathway in mice promotes autism-like phenotypes in offspring. Science. 2016;351:933-9. 
21. Moher D, Liberati A, Tetzlaff J, Altman DG, PRISMA Group. Preferred reporting items for systematic reviews and meta-analyses: the PRISMA statement. BMJ. 2009;339:b2535.

22. Sonuga-Barke EJS, Brandeis D, Cortese S, Daley D, Ferrin M, Holtmann M, et al. Nonpharmacological interventions for ADHD: systematic review and meta-analyses of randomized controlled trials of dietary and psychological treatments. Am J Psychiatry. 2013;170:275-89.

23. Higgins JPT, Thompson SG, Deeks JJ, Altman DG. Measuring inconsistency in meta-analyses. BMJ. 2003;327:557-60.

24. Riley RD, Higgins JPT, Deeks JJ. Interpretation of random effects metaanalyses. BMJ. 2011;342:d549-d549.

25. Warren RP, Margaretten NC, Pace NC, Foster A. Immune abnormalities in patients with autism. J Autism Dev Disord. 1986;16:189-97.

26. Yonk LJ, Warren RP, Burger RA, Cole P, Odell JD, Warren WL, et al. CD4+ helper T cell depression in autism. Immunol Lett. 1990;25:341-5.

27. Denney DR, Frei BW, Gaffney GR. Lymphocyte subsets and interleukin-2 receptors in autistic children. J Autism Dev Disord. 1996;26:87-97.

28. Ferrante P, Saresella M, Guerini FR, Marzorati M, Musetti MC, Cazzullo AG. Significant association of HLA A2-DR11 with CD4 naive decrease in autistic children. Biomed Pharmacother Biomed Pharmacother 2003;57:372-4

29. Enstrom AM, Lit L, Onore CE, Gregg JP, Hansen RL, Pessah IN, et al. Altered gene expression and function of peripheral blood natural killer cells in children with autism. Brain Behav Immun. 2009;23:124-33.

30. Mostafa GA, Al Shehab A, Fouad NR. Frequency of CD4+CD25high regulatory T cells in the peripheral blood of Egyptian children with autism. J Child Neurol. 2010;25:328-35.

31. Saresella M, Marventano I, Guerini FR, Mancuso R, Ceresa L, Zanzottera M, et al. An autistic endophenotype results in complex immune dysfunction in healthy siblings of autistic children. Biol Psychiatry. 2009;66:978-84.

32. Onore C, Enstrom A, Krakowiak P, Hertz-Picciotto I, Hansen R, Van de Water J, Ashwood P. Decreased cellular IL-23 but not IL-17 production in children with autism spectrum disorders. J Neuroimmunol. 2009;216:126-9.

33. Ashwood P, Krakowiak P, Hertz-Picciotto I, Hansen R, Pessah IN, Van de Water J. Altered T cell responses in children with autism. Brain Behav Immun. 2011;25:840-9.

34. Wasilewska J, Kaczmarski M, Stasiak-Barmuta A, Tobolczyk J, Kowalewska E. Low serum IgA and increased expression of CD23 on B lymphocytes in peripheral blood in children with regressive autism aged 3-6 years old. Arch Med Sci AMS. 2012;8:324-31

35. Ahmad SF, Zoheir KMA, Ansari MA, Nadeem A, Bakheet SA, Al-Ayadhi LY, et al. Dysregulation of Th1, Th2, Th17, and T regulatory cell-related transcription factor signaling in children with autism. Mol Neurobiol. 2016. https://doi.org/10.1007/s12035-016-9977-0.

36. Moaaz M, Youssry S, Elfatatry A, El Rahman MA. Th17/Treg cells imbalance and their related cytokines (IL-17, IL-10 and TGF- $\beta$ ) in children with autism spectrum disorder. J Neuroimmunol. 2019;337:577071.

37. Nadeem A, Ahmad SF, Attia SM, Al-Ayadhi LY, Al-Harbi NO, Bakheet SA Dysregulation in IL-6 receptors is associated with upregulated IL-17A related signaling in CD4+ T cells of children with autism. Prog Neuropsychopharmacol Biol Psychiatry. 2020;97:109783.

38. Ribeiro M, Brigas HC, Temido-Ferreira M, Pousinha PA, Regen T, Santa C, et al. Meningeal $\gamma \delta T$ cell-derived IL-17 controls synaptic plasticity and short-term memory. Sci Immunol. 2019. https://doi.org/10.1126/sciim munol.aay5199.

39. Sakai Y, Kassai H, Nakayama H, Fukaya M, Maeda T, Nakao K, et al. Hyperactivation of mTORC1 disrupts cellular homeostasis in cerebellar Purkinje cells. Sci Rep. 2019;9:2799.

40. Chapman NM, Zeng H, Nguyen T-LM, Wang Y, Vogel P, Dhungana Y, et al. mTOR coordinates transcriptional programs and mitochondrial metabolism of activated Treg subsets to protect tissue homeostasis. Nat Commun. 2018:9:2095.

41. Crino PB. The mTOR signalling cascade: paving new roads to cure neurological disease. Nat Rev Neurol. 2016;12:379-92.

42. Rosina E, Battan B, Siracusano M, Di Criscio L, Hollis F, Pacini L, et al. Disruption of mTOR and MAPK pathways correlates with severity in idiopathic autism. Transl Psychiatry. 2019;9:50.

43. Dai Y-X, Tai Y-H, Chang Y-T, Chen T-J, Chen M-H. Increased risk of atopic diseases in the siblings of patients with autism spectrum disorder: a nationwide population-based cohort study. J Autism Dev Disord. 2019;49:4626-33.

44. Walker JA, McKenzie ANJ. TH2 cell development and function. Nat Rev Immunol. 2018:18:121-33.

45. Palomares O, Yaman G, Azkur AK, Akkoc T, Akdis M, Akdis CA. Role of Treg in immune regulation of allergic diseases. Eur J Immunol. 2010;40:1232-40.

46. Lan F, Zhang N, Bachert C, Zhang L. Stability of regulatory T cells in T helper 2-biased allergic airway diseases. Allergy. 2020;75:1918-26.

47. Bjørklund G, Pivina L, Dadar M, Meguid NA, Semenova Y, Anwar M, Chirumbolo S. Gastrointestinal alterations in autism spectrum disorder: what do we know? Neurosci Biobehav Rev. 2020;118:111-20.

48. Iglesias-Vázquez L, Van Ginkel RG, Arija V, Canals J. Composition of gut microbiota in children with autism spectrum disorder: a systematic review and meta-analysis. Nutrients. 2020. https://doi.org/10.3390/nu120 30792.

49. Sun S, Luo L, Liang W, Yin Q, Guo J, Rush AM, et al. Bifidobacterium alters the gut microbiota and modulates the functional metabolism of T regulatory cells in the context of immune checkpoint blockade. Proc Natl Acad Sci USA. 2020;117:27509-15.

50. Reed MD, Yim YS, Wimmer RD, Kim H, Ryu C, Welch GM, et al. IL-17a promotes sociability in mouse models of neurodevelopmental disorders. Nature. 2020;577:249-53.

51. Brodin P, Davis MM. Human immune system variation. Nat Rev Immunol. 2017;17:21-9

52. Sun X, Elston R, Morris N, Zhu X. What is the significance of difference in phenotypic variability across SNP genotypes? Am J Hum Genet. 2013;93:390-7.

53. Mascha EJ, Vetter TR. Significance, errors, power, and sample size: the blocking and tackling of statistics. Anesth Analg. 2018;126:691-8.

\section{Publisher's Note}

Springer Nature remains neutral with regard to jurisdictional claims in published maps and institutional affiliations.

Ready to submit your research? Choose BMC and benefit from

- fast, convenient online submission

- thorough peer review by experienced researchers in your field

- rapid publication on acceptance

- support for research data, including large and complex data types

- gold Open Access which fosters wider collaboration and increased citations

- maximum visibility for your research: over 100M website views per year

At $\mathrm{BMC}$, research is always in progress.

Learn more biomedcentral.com/submissions 